Fintech strategy: E-Reputation

Salvatore Moccia, UNIR - La Rioja, Spain, Founder FinTechNews.org

Maria Rodriguez García, University of Valencia

*Igor Tomic, St. John's University

*Corresponding author, email: tomici@stjohns.edu 


\section{FINTECH STRATEGY: E-REPUTATION}

\subsection{INTRODUCTION}

Digital communications is increasingly taking on a larger role in terms of its impact in our social interactions, as well as its influence on corporations and the economy. According to Entschew \& Suchanek, (2017), "the promised effects of the digitalization of communication are to save time and create more freedom of action". People are spending more and more time online. According to the World Economic Forum (2016), there are 3 billion internet users, 2 billion active social media users, and more than 1.6 billion mobile social accounts. Digital media consumption for private and professional motives is more and more integrated, with individuals using digital media to move seamlessly back and forth between work and personal activities.

As a result of this, it is not only advantageous, but necessary, for organizations to take into account their e-reputation as part of their overall strategy and to maintain competitive advantage (Dutot et al., 2016). Social networks and online outlets, such as blogs, have given customers and citizens a venue to bring attention to issues they feel need to be addressed by organizations (Van Montagu, 2018). Given the global visibility and reach of social media, financial services in general and, specifically fintech firms, are often influenced by opinions on various platforms (Deephouse, 2000).

The recent GlobeScan global public opinion research (GlobeScan Radar, 2017), the level of trust remains very low towards global companies, national governments and especially the press and media, making it harder to engage in broad societal debates on the role of institutions in society. Trust often appears to be a feature that enhances the wellfunctioning of management operations in business dyads. According to Gronroos (2000), "the importance of trust can be explained by the fact that it is seen as phenomenon which contributes to the strength of inter-personal relationships, intra-organizational relationships and inter-organizational relationships in business dyads." And trust is closely related to reputation.

Corporate reputation is an assessment of financial and social impacts a firm earns over time. Tarnished image of a firm is difficult to repair and conducting business with a bad reputation becomes a heavy burden, quickly resulting in poor margins and falling value of company's shares. There is not surprise that companies we consider best have a good reputation.

\subsection{What is e-Reputation?}

A corporation's reputation consists of the overall perceptions that important stakeholders have about the organization, such as what they believe the organization stands for and 
what they associate it with; stakeholders can include customers, employees, media, communities, etc. (Chun, 2005). Just as marketing is continuously evolving given new digital media campaigns, social networks, and other Internet and mobile technologies, the definition of a corporation's reputation is developing to consider their e-reputation (Höflinger et al., 2018). Corporate image management has been described as a development process involving corporate personality, which affects corporate identity and, in turn, corporate image (Abratt, 1989). Given the pervasiveness of our digital communications, corporations must consider their Internet presence in their reputation management process. Initially, the focus for a company's reputation online was on their corporate website content, such as mission and vision statements (Chun \& Davies 2001). E-reputation is much broader in scope and includes insights from social media platforms, blogs, and all other types of communications facilitated by the Internet and mobile devices. A study by Dutot and Castellano (2015) arrived at fours dimensions that defined a firm's e-reputation, including: characteristic of the brand, website quality, service quality and e-commerce experience, and opinions / recommendations on social media.

\subsection{Objective and method}

In this paper, we investigate the role of e-communications in an organization's strategy, as well as discuss how analytics and modeling techniques are used to take advantage of the digital media content. In addition, we review the historical reputational challenge banks experienced in order for the Fintech firms to avoid past errors. That requires the adoption of strategy that would ameliorate and solidify a reputation quickly, and thus improve the firms' future performance.

\subsection{How is this paper organized?}

In section 2.0 we describe briefly the history of banks' reputation that over time faced many challenges. It took a long time for that reputation to improve and at present it is relatively high when compared to many other industries. In section 3.0 we address the entry of financial technology that should improve banks' reputation. Reputation is enhanced by creating a strong of E-reputation via the usage of big data analytics techniques. In section 4.0 we explore strategies that improve E-reputation.

\subsection{REPUTATION OF BANKS: A CHALLENGING HISTORY}

Financial technology firms operate in the banking environment. Some of them are a part of a bank, others cooperate with a bank and some are independently providing financial services. As they are challenging the industry with new approaches, they will need to develop a solid reputation. To understand their reputation and provide a superior strategy for improving it, one need to reflect on the journey banks had over time, to anticipate potential situations that Fintech firms may encounter.

In the early history of banking activities, bank's reputation depended much on the reputation of their owners, their conduct, and ability to deliver on promises made. Starting in the 20th century banks' reputation became a function of two items: A strong internal 
policies that assure care of customers, and that certainly consists of having professional people, processes, and systems. The other item, equally important, consists of regulatory rules that promote safety, viability, and safety of banks. Despite all this, banks' reputation in the 20th century had a challenging history, and not all of it is due to the internal management of a bank but also of governmental policies and ever changing economic circumstances.

The early example of solid banking reputation comes from a society named "the Poor Fellow-Soldiers of Christ and of the Temple of Solomon," better known today as the Knights Templar. In the 12th and 13th century they became the most organized global bankers and were pathbreakers in banking service and bank reputation. Templars held a respectable position is society and they could move freely across borders. The respectable position gave them access to practically anyone, from kings to merchants and they earned the highest reputation for honesty, accuracy, and security of funds as their solid fortifications were always guarded. In addition, they provided a variety of services: Sums of money could be advanced between two cities without the movement of cash; you could make a deposit in London and withdraw it in Jerusalem, using a letter of credit (Buckley and Nixon, 2009) All this would not be possible without a strong reputation; it is because of it that they did more than anyone before the 12 century. Throughout the later Middle Ages, after the Temples were disbanded, they served as an example to those in banking with respect to trust and reputation.

History of banking contains many bank failures or crisis where banks engaged in riskier activity, unknown to their customers, and ended up in a bankruptcy. Some banks took large risk financing colonial expansion and exploring new naval trade routes to obtain a variety of products. Others overextended credit and went bankrupt when a small disturbance in the markets occurred.

In the early 20th century, stories of people losing a farm or business due their inability to make a loan payment, amplified by similar newspaper reports and unethical banking characters in fictional literature, contributed to a steady negative reputation for banks. While banks loans made many business prosper, the negative images had a more powerful effect than a content fat banker smoking a cigar; a caricature shown often in the daily press in from 1900 through the early 1930's. This troubled reputation was reinforced, although not due to the fault of bankers, with a fact that a false rumor could start a run on a healthy bank and even affect other banks in the area, as seen in the Great Depression. The lack of trust in banks meant that many people chose not to depend on banking services, thus banks had fewer depositors, and that limited banks' lending activity and economic growth.

The first salvation of bank's reputation on the regulatory side came from the fact that in the 1930's in the US the FDIC provided insurance on banking deposits, meaning that deposits (up to a limited amount) were totally protected in case bank management became reckless. The public assurance of safety of their deposits eliminated bank runs 
and overall increased the stability of the banking system to a high degree; adding to an increase in trust in banking institutions. As more people started using banks, the increase in deposits stimulated lending thus supporting the economic growth after WW II. As other countries adopted the insurance on deposit policy, it helps banks almost everywhere to increase the usage of bank services. This, combined with rare bank failures improved banks' reputation.

Since WW II some individual banks faced challenges from time to time, and several countries experienced high inflation, trade issues, and contagion, but there was no major global banking crisis: In the 1980's in the US, a smaller banking sector (Savings \& Loans) faced many bankruptcies and new regulation stabilized this sector by 1991. It seemed that regulators and policy makers can address difficulties when they arise, and therefore improved regulation served to ameliorate banks' reputation. In addition, investment in the community and good relationship with local business were enough to fortify banks' reputation. The reputation was enhanced by cultivating face-to-face customer relations (Palm, 2012).

By 2008, the economy overheated and both corporate and banking sectors contributed to it. The US economy was under stress as excessive leverage (allowed by regulators), very relaxed mortgage condition with improper documentation, large increase in derivatives structured carelessly while approved by rating agencies, and combined with other events, formed a perfect storm that engulfed much of the world as it culminated in what we refer today as the Great Recession.

The Great Recession's severity surpassed forecaster expectations as at least 4 million lost their homes in the US and many globally. The US public blamed the recession on actions of banks and financial institutions and on policymakers as well. With respect to banks and financial institutions, the anger resulted from failures in the foreclosure process; rate-rigging settlements in London's Interbank Offered Rate (Libor); compensation of executives, their bonuses and golden parachutes unrelated to solid performance. The recovery from that recession added to the public anger as massive infusion of public funds were used to aid bankers, while distressed households were left to pay the price (Bloom, 2013). In tense times policy makers were too timid when it came to communicating that the banks rescue is important if there is going to be an economic recovery - no wonder that the public saw a bias in rescue policy.

Researchers brought up issues that suggested that monetary policy that had been used to expand or contract economic activity via interest rates, did not do enough to assure financial stability (Tomic I. and Angelidis J. 2018). Thus the new regulation imposed by Basel III and Dodd-Frank laws brought new regulatory tools to strengthen the stability of banks and large financial institutions: The new rules impacted managerial behavior, raised capital adequacy, 'stress tested' large financial holding companies to check on their survivability during potential economic shocks. By creating tools to assure banks' 
stability under times of economic stress, the trust in banks and their financial affiliates was lifted.

\subsection{Banks' reputation at present}

Globally it seems that the banks reputation has improved since the Great Recession. The Financial Services Reputation Index (2018) reported that in the last decade an increase in trustworthiness of banks in a variety of countries occurred. Furthermore, the surveys indicate that the clients believe that bank reputation could increase further if improvements in transparency, quality of services and consistency, take place. While banks traditionally focused on products, it seems that even at present the higher focus should be placed on customer needs (Lizarzaburu \& del Brío, 2018; Gangi et al., 2019). In 2018 for example, it was rather surprising that the factors such as data breaches or system failures restricting access to funds, seemed less important compared to interaction with customers and employee treatment. It seems that in the public's eye bank reputation would increase if there is more equality in salaries by gender, more equal opportunities based on race and gender, no punishment of whistleblowers, and less sexual harassment by management (Garver, 2018).

According to a most recent survey (2019), consumers trust banks most. The nCipher survey results show that people trust the financial sector in general and their banks in particular more than any other industry vertical or organizations that touch their data. A third of those surveyed said they trust financial services organizations most to protect their personal data. More than half $(52 \%)$ said they trust their banks specifically to protect their data. This indicates that people place much higher trust in banks and other financial institutions than they do in other business verticals and the public sector. Less than a quarter (23\%) of those surveyed trust organizations in the legal profession to handle their data. And only about $20 \%$ of nCipher survey participants said they trust their cellular provider or the government to secure their personal data.

While the nCipher survey results indicate people have relatively high trust in banks, the research also illustrates that trust can be fleeting. It's easy for trust to be eroded or disappear completely. For example, recently (February 2018), India has been gripped by the scandal involving billionaire jewelers and the state-owned Punjab National Bank. Just four days after Punjab National Bank's stunning \$1.77bn fraud announcement, its peer Bank of Baroda approached state investigators with another alleged scam relating to trade finance - reinforcing fears about Indian state-owned banks' monitoring of client risk. Following the scandals and the street protests, Punjab National Bank on May 62018 , announced its plans to rely on Artificial intelligence (Al) for reconciliation of accounts and incorporate analytics for improving the audit systems as it seeks to clean up the process and counter fraud in the near future. PNB managing director Sunil Mehta said in a statement that, "The 'business remodeling' brought alive by changes at PNB is essential 
to ensure that the bank continues to grow and compete with its peers better," and elaborated on several steps that would reduce human intervention.

In the US and abroad banks' reputation may further improve with more inclusion. In the US families earning below $\$ 30,000$ are financially marginalized, meaning that many in this group barely use any banking service. The primary reason was a dislike for dealing with financial institutions (Bloom, 2012). To reduce poverty, it is rather important to expand the inclusion, but that requires a new way of relating to this segment of customers - not an impossible task.

\subsection{THE DIGITIZATION OF BUSINESS}

According to Parnell (2014), the Internet has changed how strategic managers evaluate a given situation and use this assessment to inform strategic decisions. In particular, the author highlights the following key interrelated strategic factors: (1) trend toward information symmetry, that occurs when all parties share the same information concerning that transaction; (2) the use of the Internet as a distribution channel for nontangible goods and services; (3) the increase of the speed of transactions and processes; (4) the interactivity between customers and firms, that increases the exchange of information, rumors, and bad news; (5) potential for cost reductions and cost shifting, thereby enhancing flexibility.

Conklin (2011) notes that information technologies have enabled the collection, analysis and distribution of a numerous kinds of information. Given this new advantage, management can make more well-informed decisions. In terms of strategy, since managing a company is so closely tied to managing technologies, technologies are becoming more influential on a company's strategic decisions. As Porter (2001) noticed earlier, "Internet changes everything, rendering all the old rules about companies and competition obsolete".

The complex modern business environment is characterized by an exceptional rise of digital stakeholder empowerment that needs to be continuously fed with opinions, viewpoints, judgements, and verdicts (Argenti \& Barnes, 2009). Online communication platforms, such as blogs and social networks, transformed communication in the business environment (Loebbecke \& Picot, 2015).

A recent survey conducted by McKinsey (2015) highlights that social tools are used much more often in some processes and activities than others: namely, in customerengagement processes such as public relations, customer relationship management, and the execution of marketing activities. Survey results indicate that the use of social tools have influenced processes related to developing customer insights and competitive intelligence. Another McKinsey survey (2016) on how social tools are reshaping organizations finds the following: executives report that the business use of social tools is nearly universal (93 percent compared to 82 percent of the previous surveys, 2013, 
and 2015). They emphasize the importance of real-time interactions, the ability to collaborate with specific groups, and cross-platform availability for their companies.

\subsection{Customers effect change through social media}

One famous case of how companies are influenced by social media, is the Kit-Kat story. Greenpeace, an environmental group, created a social media attack on the Kit Kat brand of Nestlé in March of 2010. Greenpeace released a YouTube video that brought awareness to the environmentally harmful practices involved in the production of palm oil used by Nestlé related to unsustainable forest clearing practices (Steenkamp 2017). The first reaction from Nestlé's was to request that the video be removed from YouTube due to copyright infringement, since the video featured Kit Kat's signature slogan. However, Greenpeace in turn posted the video on Vimeo. The video eventually made it onto YouTube again and garnered a total of 180,000 views (Financial Times, 2012). To make a very-long story short, after two months, the company suspended sourcing from the supplier accused of improper forest clearing, and joined the Roundtable for Sustainable Palm Oil (RSPO), a partnership of companies and other interested groups whose goal is to encourage sustainable production of palm oil. In addition, Nestlé updated its marketing and communications strategy to include constant monitoring of social media sentiments. Another famous case is the use of the social platform foursquare by Jimmy Choo in April 2010. The luxury footwear brand used the platform to combine games and geolocation to organize a treasure hunt in real time. A pair of Jimmy Choo shoes were hidden in different places in London and participants were asked to follow the campaign and get there before the pair changed location. That was the first adventure of luxury brand to combine on-line and off-line marketing campaigns. Geolocation information can be useful for marketing campaigns that are based on the location of users, and other user-centered applications that can utilize GPS coordinates.

Ana Riera is a 19-year old Spanish girl who has forced the giant Zara to reconsider some decisions on two separate issues, using the social platform change.org. In November 2015 she launched, through the cited platform, a campaign to banish "anorexic mannequins" from Inditex stores (Zara's holding) because they promote "an impossible beauty ideal". The campaign attracted a large numbers of supporters, both in Spain and abroad, collecting 111,822 signatures, which prompted the fashion giant to respond [thelocal.es 2015]. Gap and La Perla have also been pressured by social media regarding their mannequins. In 2016, Ana took on Zara again in a campaign to get Zara to stock larger sizes [thelocal.es 2016].

Not only have business leaders been influenced by using social media to reshape their organizations, but so have political leaders. In 2016, a young Cambodian man, Kong Chamroeun, was imprisoned and facing criminal charges for allegedly stealing company property worth US\$80. His family insists that he is innocent of this crime. His girlfriend claims that Chamroeun was extorted for $\$ 2,000$ by police in order to not press charges. Then, the girl made the decision to use her smartphone to appeal to Prime Minister Hun 
Sen directly. She posted a video on the Prime Minister's Facebook page that exposed the extortion attempt. This resulted in Chamroeun getting free and charges dropped the next day. This video appeal went viral and since then, the Prime Minister has welcomed the public to contact him on Facebook regarding government corruption issues (Chan 2016).

\subsection{Digitization, Reputation and Financial Technology}

While recent banks' recent reputation has be on the rise, financial technology has been deployed in banks and financial services, with the purpose of producing a better quality product, quick and efficient service, that is easily available to all. The new technology, is very promising and resolves many issues that were more challenging in the past. For example, according to LenditBlog (2018), in Spain more than 69\% of online shopping carts were abandoned. In fact, Spanish shopping cart abandonment represented a missed total of approximately 46 billion euros. In order to capture these lost opportunities and control credit risk, a fintech - Aplazame - was developed to correctly verify the identity of customers who applied for credit - quickly and securely. The outcome was the following one. By integrating Mobile Verify ${ }^{\circledR}$, Aplazame was able to verify a customer's identity in fewer than 20 seconds, allowing them to offer instant, secure and streamlined financing in connection with e-commerce purchasing. The impact was a $20 \%$ increase in conversion rates, and an $88 \%$ reduction in identity fraud.

Another use of new technologies in fintech is the interaction with customers. As users increasingly migrate to digital channels, banks who haven't invested in creating a strong digital presence run the risk of losing relevance amongst their customer base. Digital banking provides an opportunity to interact more frequently with customers, and with much higher customer satisfaction levels. To compete in a digital world, financial actors must offer smart digital products and services that are easily accessible over every device. They need a platform that supports their efforts to stay competitive by providing innovative digital excellence. With the right platform in place, a bank can create superb customer experiences, react swiftly to market changes and capitalize on unexpected marketing opportunities. All of this begins with noting the pain points for the customer and solving these with the digital banking platform. (Backbase, 2018).

With present financial technology businesses have the access and capability to collect customers' views, feedback and opinion about products or services, and value customers expect from offered services. Not only this, organizations are now able to identify untold information about their products, services or opportunities and use that in producing new and innovative products or services (Malviya and Malgrem, 2019).

\subsection{ANALYSIS: BIG DATA ANALYTICS TECHNIQUES AND E- REPUTATION}


Some Big Data analytics techniques can be used to monitor, trace, improve and raise ereputation in business. Fintech companies should use some of these techniques to avoid distrust in their services. Big Data analytics techniques can be grouped into different categories:

- Statistical analysis

- Social network analysis

- Semantics

- Data visualization

- Predictive analysis

- Other analysis

Statistical analysis can be used to process and analyze the huge volumes of data financial transactions are producing and help to interpreter their implications. For example, Capital One bank uses A/B testing (statistical hypothesis testing) extensively. In 2018, they used a A/B testing technique to redesign the website.

Old Site Navigation, in use since 2015 Site Redesign

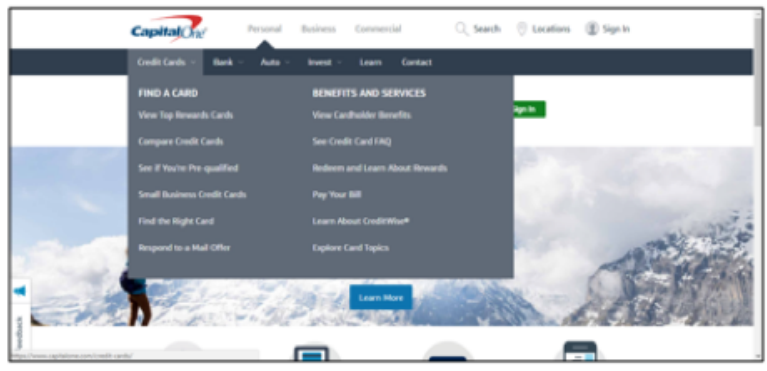

New Site Navigation Concept; A/B test launch 5/30
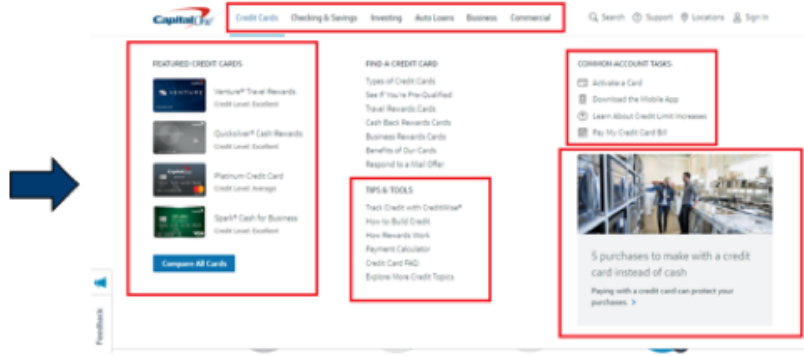

Table 1: Capital One old site vs. Capital One new one (Source: Capital One web site)

According to the company's experience (2018), A/B testing can b put in practice to drive a redesign doing the following:

- Collect KPI, anonymous page interaction data from previous tests.

- Identify areas and interactions where control and test vary.

- Assess opportunity of closing or exceeding the gap-is this worth doing.

- Formulate a hypothesis.

- Figure out how to test the hypothesis quickly and cheaply to learn if the hypothesis is valid.

- Figure out how many people need to see the test.

- Build and ship test. (ABS-Always Be Shipping)

- Collect data and conduct analysis.

- Iterate and continue.

Social Network Analysis, also known as SNA, is a technique that could be used for extracting insightful information from unstructured data. SNA is the mapping and measuring of relationships and flows between people, groups, organizations, computers, 
URLs, and other connected information/knowledge entities. For example, the financial sector could use those new technology advances in order to prevent and detect digital identity fraud. SNA (Social Network Analysis) makes it possible, for example, to detect fraudulent connections, unreliable data patterns or irregular activities. The latest applications also make it possible to identify a trust level for a given user, that is, how likely they are to repay a loan or if they are who they say they are, based on a holistic approach to the individual's data on the Internet. Put simply, the new on-line verification procedures incorporate a process that validates the email provided by the individual for an onboarding process or other transactions. Based on this email, information is tracked on associated social media and evidence is collected by means of an algorithm in order to provide more reliable validation, including a fraud score. This new functionality, together with those already implemented such as testing of document security measures, liveness testing, and biometric facial recognition, make it increasingly difficult for scammers to steal identities, while ensuring security levels that benefit both companies and users (Icarvision, 2017).

A Case Study on the use of SNA in the financial sector is the following one provided by a fintech company called G-Square (2019). The client was a large private sector bank in India with a large savings and current account base. Along with their own products, client also sells third party products like Life Insurance, Health Insurance, Mutual Funds etc. Client has been selling these products with sales push strategy across all the regions. The client wanted to identify the potential customers from their existing customer base, to whom they can sell targeted third-party products. The client also wanted to know when and how to target these prospects. The Fintech G-Square developed a solution based on the analysis of the demographics, buying pattern \& banking behavior of customers. The tool was able to identify most important factors which affects the propensity of buying the third-party products. Using these factors, G-Square developed a robust Propensity Model using 'R' tool. A few thousand customers were identified with the help of propensity model, who have very high propensity to buy targeted products. The company also analyzed the time series data to identify the time period for targeting set of prospective customers. The solution helped client to focus on right customers which was giving them significant lift in the third-party products than the traditional approach.

Another case study is the introduction by BSE - Asia's first stock exchange - in 2016 of a data analytics based systemic solution that relies on artificial intelligence mechanism to track news related to listed companies on digital media using social media like twitter etc. The primary objective of verification the mechanism is to detect and mitigate potential risks of market manipulation, rumor, and reduce information asymmetry arising from it on digital media platforms, including social media. It provides accurate information involving listed companies and BSE through the exchange website for the benefit of investors.

Semantics is the branch of linguistics and logic concerned with meaning. The use of social media and the democratization of the Internet have given the opportunity to extract 
meaning and information from huge amounts of text without reading them manually. In particular, Real Time Intention (RTI) - a text expression signifying an intent to perform an activity in the near future - has started to gain a lot of popularity (for example, Amazon's recommendation). Several financial institutions are using RTI in replacing a big part of their support staff with automated chatting box. According to AustralianFintech (2019), over the past year, many experiments have moved into production. The technology is being used to deliver personalized banking experiences to customers and helping bank staff make better decisions. For example, National Australia Bank's "virtual banker" can recognize 13,000 variations of 200 common questions from its business banking customers, while NAB's digital bank UBank has created RoboChat with IBM Watson to respond to questions on home loans. Fintech companies like, for example Personetics, are developing semantics system to deepen the understanding of customer behavior and design more innovative, responsive and responsible digital banking services.

There are many reasons to use a chatbot for consumer engagement in banking.

- Cost savings, since chatbots are relatively inexpensive to develop and maintain compared to human equivalent;

- Reliability, since Al connected to chatbots is evolving to better understand not only the speech, but also what is the intent in that speech and, moreover, to provide solutions that can work with unstructured data such as conversations with clients, sentiments, feelings, customer interactions, obligations with regard to a legal document or automated invoice processing processes.

- Ease of use, since chatbots are more intuitive, quick and personalized;

- Predictions, since chatbots use of customer's data allow them to make recommendations based on spending habits, credit scores, etc., and give advice for better money management.

Data Visualization presents data in a graphical format. It makes decision making easy, as people are able to see the analytics/findings presented visually. With the help pf dynamic data visualization, it is possible to identify the factors that influence customer behaviors and buying patterns.

For example, in 2018, the fintech Dimebox releases new User Interface (UI) with infinitely scalable data visualization capabilities. With this release, users can interactively explore billions of data records, without sacrificing performance. Market research revealed that payment service providers want to offer their customers a multitude of information at once, affording them the freedom to choose what to focus on. The non-modal structure of the $\mathrm{UI}$ includes large-scale representations like graphs and tables, and detail panes containing all elements of a given item, accessible concurrently in the same view.

Another example of fintech providing financial solutions using Data Visualization is the solution provided by Infragistics (Cranbury, 2019), a provider of UI components, that has joined forces with the Adaptable Blotter, the market-standard HTML5 DataGrid Add-on from Adaptable Tools, to offer integrated, live charting within the DataGrid, something not 
previously available for financial users. According to the company, the unique partnership allows effortless switching between charting and table views together with a host of other features that will enable users to view and manipulate their data in ways not previously possible. According to Barry Gould, a Financial Services Industry Expert, the tool is a real game-changer in terms of what is available on the financial desktop. It can offer a strategic advantage to help visualize and then be able to quickly spot data patterns that can help make critical decisions in a very competitive financial market.

Predictive analysis systems are techniques used to analyze past data, recognize patterns and applying this information to the real-time data to identify what will happen next and suggesting appropriate options to the user. Predictive analytics is one of the most important trends affecting FinTech. There are a number of applications for predictive analytics. One of the biggest uses is fraud prevention. A number of new predictive analytics algorithms have helped fintech companies identify potential fraudsters. Their fraud scoring algorithms use a number of variables, such as the nature of IP addresses, association with suspicious email addresses, region of the user and the credibility of the names on their accounts. Fintech companies also use predictive analytics to conduct risk analysis of potential borrowers (Girijala, 2018).

Fintech lending platforms have entered the unsecured personal loan space and have a potential to fill this unmet demand for credit. Over the past decade, online alternative lenders have evolved from platforms connecting individual borrowers with individual lenders to sophisticated networks featuring institutional investors, direct lending (on their balance sheet), and securitization transactions. The use of alternative data sources, big data and machine learning (ML) technology, and other complex artificial intelligence (AI) algorithms could also reduce the cost of making credit decisions and/or credit monitoring and lower operating costs for lenders (Jagtiani \& Lemieux, 2017). Fintech lenders could potentially pass on the benefits to the borrowers. Some Fintech lenders have developed their own proprietary complex ML algorithms that use Big data and alternative data to evaluate borrowers' credit risk. Through this new approach to credit risk evaluation, some consumers with a short credit history, that may not satisfy a bank's traditional lending requirements, could potentially get a loan from an online alternative lender (Jagtiani \& Lemieux, 2018).

Finally, fintech can use also predictive analytics to improve financial services with fast and accurate predictions trying to find answers to questions like the following ones: Who will need a loan next week? Who will buy financial service $X$ ? Who will get the new credit card? Who will convert to premium? Who will make a transaction tomorrow? Who will default on a loan? Who in group B won't default? Who will change credit group?

For example, FinTech company Endor's predictive analytics platform technology allows a fully automated, scalable, real-time, encrypted prediction system to be implemented across all veins of the business - the business culture, decision processes and operations. 
In short, the use of Big Data by FinTech companies enable nuanced understandings of the large amounts of data maintained by and available to banks and other financial actors. Such analysis can facilitate deeper and real-time insights into internal operations and external market dynamics, informing potential strategies across various departments.

\subsection{CONCLUSION}

While corporation's reputation consists of the overall perceptions that stakeholders have about an organization, in this paper we focused on the E-reputation, which also contains insights from social media platforms, blogs, and all other types of communications facilitated by the Internet and mobile devices. Four dimensions describe well the source of E-reputation: characteristic of the brand, website quality, service quality and ecommerce experience, and opinions / recommendations on social media.

A brief history of Banks' reputation was presented to show the various difficulties that banks had with their reputation over time to give us the basis of challenges financial institutions face. While Banks' reputation at present is much improved, financial technology can certainly ameliorate that reputation. Today an improvement in reputation also means to develop a solid E-reputation.

The world in which today's businesses operate has become not only riskier but also more volatile, uncertain, complex, ambiguous, rapid, and radical (VUCARR). Organizations that are managed using traditional ways of operating will be hampered in their ability to survive (Lee \& Trimi, 2018). In contrast, success depends on a company's ability the understand the new elements of the environment that, coupled with business model innovation, will unleash the initiative, imagination, creativity, innovation needed to survive in this VUCARR world.

Among those elements, we must mention trust and reputation that are still fundamental characteristics of a successful business relationship. In addition to that, we believe they are the only way to be a successful business in the long-term. In fact, seamless access to information has made consumers more sophisticated and able to discern between correct and incorrect information. Pervasive access has increased their confidence in understanding and using technology. Today's users learn from the internet through powerful and free sites such as the Kahn Academy or thousands of other free websites with verified content. Users are empowered to detect and understand scams through an increasingly reliable network of online reviews and online communities, which are difficult (although not impossible) to manipulate if the users complete the due diligence in searching for multiple sources of information. This increased access to information can ultimately increase customers' sophistication.

Remaining competitive in this rapidly and constantly changing environment is becoming a complex task. Traditional tools and strategies get quickly supplanted by better ways to meet customer needs. Established players, such as banks or similar financial institutions, 
are facing new competitors who understand consumer expectations better and are equipped to meet emerging needs with new technologies (Moccia, Tomic and Passerini, 2018). In our paper we presented some Big Data analytics techniques that could be used to monitor, trace, improve and raise e-reputation in business. Financial actors, whether they are fintech or not, should use some of these techniques to avoid distrust in their services.

So where are we heading in the near future? Financial actors need to be engaged with customers through different technologies in order to be always able to deliver a better service and, foremost, to maintain and/or effect positive change in their e-reputation.

\section{References}

Abratt, R. (1989) A New Approach to the Corporate Image Management Process, Journal of Marketing Management, Vol. 5, No. 1, pp. 63-76.

Argenti, P. A., Barnes, C. M., (2009), Digital Strategies for powerful corporate communications, The McGraw-Hill Companies Publishing.

AustralianFintech (2019), Chatbots just the beginning for Al in banking. Retrieved from https://australianfintech.com.au/chatbots-ai-banking/

BackBase (2018). The ROI of omni-channel digital banking. Retrieved from https://www.backbase.com/resources/roi-omni-channel-whitepaper/

BCBS, (2015), "Guidelines" (An updated framework for guidelines). Retrieved from: https://www.bis.org/bcbs/publ/d328.htm

Bloom Rasking, Sarah, (2013). Reflections on Reputation and its Consequences presented at the 2013 Banking Outlook C at the Federal Reserve Bank in Atlanta, February 26.

Capital One (2018). A/B Testing-Big Change, Not Big Bang, Retrieved from https://www.capitalone.com/tech/software-engineering/a-b-testing---big-change-not-bigbang

Castellano, S., Khelladi, I. (2016), "Reputation, Image, and Social Media as Determinants of e-Reputation: The Case of Digital Natives and Luxury Brands", International Journal of Technology and Human Interaction, 12.4, p. 48.

Coase, R.H. (1937) "The Nature of the Firm”, Economica 386, 395.

Chan, P. (2016) "Got a Problem? Contact Hun Sen on Facebook", Bangkok Post, March 28, 2016.

Chun, R. (2005). "Corporate reputation, meaning and measurement," International Journal of Management Reviews, 72, 91-109. 
Chun, R., Davies, G. (2001) "E-reputation: The role of mission and vision statements in positioning Strategy". The Journal of Brand Management, 84, 315-333.

Conklin, D.W. (2011), The Global Environment of Business: New Paradigms for International Management, Sage Publications, Thousand Oaks California.

Cranbury, N. J. (2019,), Infragistics + Adaptable Tools: Bringing Unprecedented Power to the Desktop. Retrieved from https://www.infragistics.com/about-us/in-thenews/infragistics-plus-adaptable-tools-bringing-unprecedented-power-to-the-desktop

Deephouse, D. L. (2000). Media reputation as a strategic resource: An integration of mass communication and resource-based theories. Journal of management, 26(6), 1091-1112.

Dutot, V., Castellano, S., (2015), "Designing a Measurement Scale for E-Reputation", Corporate Reputation Review, 18 (4), 294 - 313.

Dutot, V., Lacalle Galvez, E., \& Versailles, D. W. (2016). CSR communications strategies through social media and influence on e-reputation: an exploratory study. Management Decision, 54(2), 363-389.

Entschew, M.E., Suchanek, A., (2017), Digital Communication: A New Challenge for Moral Discernment, Zeitschrift Für Wirtschafts- Und Unternehmensethik, 18(3), 347-369

Financial Services Reputation Index, (2019 and 2018), "Reputation in Financial Services: Problem Solved?" Various country reports.

Financial Times (2012). "How Nestlé dealt with a social media campaign against it", Retrieved from: https://www.ft.com/content/90dbff8a-3aea-11e2-b3f0-00144feabdc0

Gangi, F., Meles, A., D'Angelo, E., \& Daniele, L. M. (2019). Sustainable development and corporate governance in the financial system: Are environmentally friendly banks less risky?. Corporate Social Responsibility and Environmental Management, 26(3), 529-547.

Garver Bob, (2018). American Banker, "Bank Reputation Fall for the First Time in Five Years: 2018 Survey," June 28.

Girijala, R. (2018). Predictive Analytics shaping FinTech. Retrieved from https://www.karmelsoft.com/predictive-analytics-shaping-the-fintech/

G-Square (2019), "Case Study 1: Customer Analytics For a large bank", https://gsquare.in/customer-analytics-large-bank/

Grant Thornton LLP, (2016), "Managing reputation risk." Retrieved from https://www.grantthornton.com/-/media/content-page-files/financial-

services/pdfs/2016/GARP/FIS-Managing-reputation-riskupdated.ashx?la=en\&hash=0547266C76ABD1A125D99C838362DC1F62859948 
Grönroos, C. (2000), Service Management and Marketing. A customer relationships management approach, John Wiley \& Sons, Chichester.

Höflinger, P. J., Nagel, C., \& Sandner, P. (2018). Reputation for technological innovation: Does it actually cohere with innovative activity?. Journal of Innovation \& Knowledge, 3(1), 26-39.

Icarvision, (2017). Social network analysis for the prevention of on-line fraud: the new fintech challenge. Retrieved from https://www.icarvision.com/en/social-network-analysisfor-the-prevention-of-on-line-fraud--the-new-fintech-challenge

Khelladi, I. \& Castellano, S. (2016) Reputation, Image, and Social Media as Determinants of e-Reputation: The Case of Digital Natives and Luxury Brands. Int. J. Technol. Hum. Interact. 12, 4 (October 2016), 48-64.

Jagtiani, J., Lemieux, C., (2017), FintechLending: Financial Inclusion, Risk Pricing, and Alternative Information, working paper. Retrieved from https://www.fdic.gov/bank/analytical/cfr/bank-research-conference/annual17th/papers/14-jagtiani.pdf

Jagtiani, J., Lemieux, C., (2018), The Roles of Alternative Data and Machine Learning in Fintech Lending: Evidence from the LendingClub Consumer Platform, working paper. Retrieved from https://www.philadelphiafed.org/-/media/research-anddata/publications/working-papers/2018/wp18-15r.pdf

Lee, S. M., \& Trimi, S. (2018). Innovation for creating a smart future. Journal of Innovation \& Knowledge, 3(1), 1-8.

LenditBlog, (2018). Case Study - eCommerce lender boosts conversion rates while cutting fraud with digital identity verification. Retrieved from https://blog.lendit.com/casestudy-ecommerce-lender-boosts-conversion-rates-cutting-fraud-digital-identityverification/

Lizarzaburu, E. R., \& del Brío, J. (2018). Corporate Social Responsibility and Corporate Reputation in Emerging Countries: An Analysis of the Peruvian Banking Sector. In Innovation and Capacity Building (pp. 55-76). Palgrave Macmillan, Cham.

Loebbecke, C., \& Picot, A. (2015). Reflections on societal and business model transformation arising from digitization and big data analytics: A research agenda. The Journal of Strategic Information Systems, 24(3), 149-157.

Malviya, A., Malmgren, M., (2019), Big Data for Managers, Routledge Publications

McKinsey, (2015). Transforming the business through social tools. Retrieved from https://www.mckinsey.com/industries/high-tech/our-insights/transforming-the-businessthrough-social-tools 
McKinsey, (2016), How social tools can reshape the organization. Retrieved from https://www.mckinsey.com/business-functions/digital-mckinsey/our-insights/how-socialtools-can-reshape-the-organization

Mitek (2019), Case Study: Aplazame boosts conversions by $20 \%$ with digital ID verification. Retrieved at https://www.miteksystems.co.uk/resources/case-studyaplazame-boosts-conversions-20-digital-id-verification?confirmed=1

Moccia, S., Tomic, I., Passerini, K., (2018), Fintech: challenges, drivers, and future opportunities, Cutter Business technology Journal, Vol. 31, No. 11/12

Survey reveals Americans trust banks most with their personal data. (2019). Retrieved from https://es.ncipher.com/about-us/newsroom/news-releases/ncipher-survey-revealsamericans-trust-banks-most-their-personal

Palm, Susan, (2012). American Banker," BankThink: Why Reputational Risk is on the Rise, Nov. 30. https://www.americanbanker.com/opinion/why-reputational-risk-is-on-therise.

Parnell, J. A., (2014). Strategic Management - Theory and Practice, Fourth Edition, Sage Publications

Punjab National Bank relies on artificial intelligence to check frauds. (2018). Retrieved from https://m.timesofindia.com/business/india-business/punjab-national-bank-to-relyon-artificial-intelligence-to-check-frauds/amp_articleshow/64056289.cms

Ross P. Buckley and Justen Nixon, (2009)." The Role of reputation in Banking," University of New South Wales Faculty and Law Research Series, paper no. 13. Retreieved from: https://www.researchgate.net/publication/228183169 The Role of Reputation in Ban king

Schmidt Bies, Susan, Governor FRB, (2006). "A Bank Supervisor's Perspective on Enterprise Risk Management," Speech at the Enterprise Risk Management Roundtable, North Carolina State University, Raleigh, North Carolina, April, 28. Retrieved from: https://www.federalreserve.gov/newsevents/speech/bies20060428a.htm

Steenkamp, J.B. (2017) Global Brand Strategy - World-wise Marketing in the Age of Branding, Palgrave Macmillan, UK.

Tomic, Igor M. and John Angelidis (2018), "Macroprudential Policies: Resolution and Continued Challenges," International Journal of Financial Research, Vol.9. No.4, October.

Williamson, O. (1985). The Economic Institutions of Capitalism. Harvard University Press.

Van Montagu, M. (2018). Science, ideology and daily life. Journal of Innovation \& Knowledge, 3(2), 66-69. 
World Economic Forum (2016). Digital Media and Society implications in a hyperconnected era. Retrieved from http://www3.weforum.org/docs/WEFUSA DigitalMediaAndSociety Report2016.pdf 